\title{
Evaluación citológica y microbiológica de lavados uterinos en bovinos con problemas reproductivos (estudio preliminar)
}

\section{Cytological and microbiological evaluation of uterine washing of bovine with reproductive problems (preliminary study)}

\author{
Milena Sánchez $L,{ }^{1}$ Microb Agrí Vet, Carolina González $C,{ }^{1}$ Microb Agrí Vet, \\ Rubiela Castañeda $S,{ }^{1 *}$ M.Sc, Adriana Pulido $V,{ }^{1}$ M.Sc, Humberto Guáqueta $M,{ }^{2} \mathrm{Ph} . \mathrm{D}$, \\ Moises Aranda S, ${ }^{3}$ M.Sc, Milton Rueda ${ }^{3}{ }^{3}$ Ph.D.
}

${ }^{1}$ Pontificia Universidad Javeriana. Facultad de Ciencias. Departamento de Microbiología, Bogotá D.C. Colombia. ${ }^{2}$ Universidad Nacional de Colombia. FMVZ, Clínica de la Reproducción. Bogotá D.C. Colombia. ${ }^{3}$ Pontificia Universidad Javeriana. Facultad de Ciencias. Departamento de matemáticas. Bogotá D.C. Colombia. *Correspondencia: castaneda.r@javeriana.edu.co

Recibido: Agosto de 2010; Aceptado: Julio de 2011.

\section{RESUMEN}

Objetivo. Determinar las características citológicas y microbiológicas de lavados uterinos de bajo volúmen en hembras con problemas reproductivos en dos hatos del Altiplano Cundiboyacense. Materiales y métodos. Se evaluaron 21 muestras de lavados uterinos de vacas con historia de problemas reproductivos procedentes de dos hatos lecheros, en el primer hato ubicado en Sibaté (Cundinamarca) se muestrearon 10 animales y en el segundo ubicado en Ventaquemada (Boyacá) se obtuvieron las 11 muestras restantes. Se realizó evaluación macroscópica y microscópica de cada uno de los lavados uterinos; para la evaluación citológica se utilizaron las tinciones de Gram y Wright. La determinación de la flora bacteriana se realizó mediante técnicas estándar en microbiología para la identificación de bacterias no exigentes, adicionalmente se realizaron pruebas de sensibilidad por la técnica de difusión de Kirby-bauer. Resultados. En la citología se observaron bacilos y cocos gram positivos, células epiteliales de descamación uterina (CEDU) y respuesta inflamatoria (RI) mediada por polimorfonucleares (PMN). Los aislamientos bacterianos correspondieron a Lactobacillus sp como flora bacteriana normal del tracto genital (16.66\%) y Klebsiella sp como flora acompañante (16.66\%); adicionalmente se aislaron bacterias patógenas causantes de problemas reproductivos como Streptococcus sp. $\beta$ hemolítico $(33.33 \%)$, Streptococcus sp a hemolítico (50\%) y Streptococcus sp. y hemolítico (50\%) y Arcanobacterium pyogenes (Corynebacterium-Actinomyces pyogenes) $(16.66 \%$ ); en un $9.52 \%$ de las muestras se observaron espiroquetas. Conclusiones. Se observó una relación directa entre el aspecto macroscópico de los lavados uterinos, la respuesta citológica y el aislamiento de bacterias.

Palabras clave: Arcanobacterium pyogenes, bovinos, enfermedades uterinas, Klebsiella sp, Streptococcus sp (Fuentes: CAB. AIMS). 


\section{ABSTRACT}

Objective. Determination of the cytology and microbiology characteristics using low volume uterine lavage in dairy cows with reproductive problems in two herds on the cundiboyacence plateau. Materials and methods. 21 uterine lavage samples from cows with reproductive problems in two dairy herds were evaluated. The herds were located in Sibate (Cundinamarca) and Ventaquemada (Boyaca). 10 and 11 cows were sampled in each herd respectively. The uterine lavages were examined both macroscopically and microscopically. The cytological evaluation was done using Gram and Wright staining. The determination of the bacterial flora was done using standard microbiological methods used for the identification of the bacteria, the Kirby-bauer diffusion test for sensitivity was also done. Results. Bacilli, cocci, desquamating uterine epithelial cells (CEDU) and inflammatory response (IR) mediated by polimorphonuclear cells were observed. Bacterial isolates were lactobacillus sp as part of normal floral (16.66\%) and Klebsiella sp as accompanying flora $(16.66 \%)$. There were also isolations of pathogenic bacteria that cause reproductive problems such as o Streptococcus sp. $\beta$ hemolytic (33.33\%), Streptococcus sp. a hemolytic (50\%) y Streptococcus sp. $\mathrm{y}$ hemolytic (50\%) and Arcanobacterium pyogenes (CorynebacteriumActinomyces pyogenes) (16.66\%); spirochaete was observed in $9.52 \%$ of the samples. Conclusions. There was a direct relationship between macroscopic appearance of the uterine lavage, citology response and bacterial isolation.

Key words: Arcanobacterium pyogenes, cattle, Klebsiella sp, Streptococcus sp, uterine disease (Sources: CAB, AIMS).

\section{INTRODUCCIÓN}

Las pérdidas económicas ocasionadas por problemas reproductivos son de gran relevancia en la industria ganadera, debido a que afectan directamente la productividad de los hatos, por ello es de suma importancia reconocer la presencia de agentes patógenos en el tracto genital de los bovinos (1).

El tracto genital de las hembras posee flora bacteriana en casi toda su extensión, a excepción del útero, ya que allí por lo general no habitan microorganismos, aunque esto puede variar de acuerdo con el estatus inmunológico del animal. La vagina por ser la parte del tracto reproductivo más expuesta, posee mayor número de bacterias, entre las cuales se pueden encontrar Gram negativas y Gram positivas (2); sin embargo, durante la gestación y el parto, el cuello uterino y el útero no se encuentran totalmente estériles, por lo que se pueden aislar microorganismos oportunistas, que producen inflamación e infección haciendo necesaria su rápida detección para prevenir problemas reproductivos esporádicos $\mathrm{y} / \mathrm{o}$ permanentes (3) y de esta forma evitar grandes pérdidas económicas.

Cabe resaltar que es de suma importancia la valoración citológica de los lavados uterinos con el objetivo de evaluar posibles alteraciones en la celularidad y determinar la respuesta inmune local de los animales (4); como lo demuestran estudios realizados en Norte América para el diagnóstico de problemas infecciosos en vacas postparto (40-60 días) que presentaron endometritis (5) y que deben ser complementados con un examen clínico completo (4). Mediante la coloración de Wright se pueden observar y determinar las variaciones 0 anormalidades en estructura y tamaño de los diferentes tipos de células, mientras que la tinción de Gram es una coloración diferencial de uso bacteriológico (6).

En cuanto a las bacterias aisladas del tracto reproductivo, éstas se clasifican principalmente en cuatro grupos: bacterias Gram positivas, Gram negativas, ácido-alcohol resistentes y 
bacilos esporo formadores $(7,8)$. En las primeras se agrupan los géneros Staphylococcus spp, Streptococcus spp, Lactobacillus spp, y Enterococcus spp; el grupo de las Gram negativas está conformado por Pseudomonas spp, E coli, Klebsiella spp, Proteus spp y Prevotella spp; Arcanobacterium pyogenes (Corynebacterium-Actinomyces pyogenes) como ácido-alcohol resistente (4) y entre los bacilos esporoformadores asociados a problemas reproductivos está el género Clostridium spp (9); otro microorganismo reportado en menor proporción es Mycoplasma spp que se caracteriza por la ausencia de pared (7).

Streptococcus sp. Se ha relacionado con diversos problemas reproductivos en bovinos, entre los que se encuentran: cervicitis, metritis y aborto; las enfermedades reproductivas postparto causadas por esta bacteria comprometen la eficiencia reproductiva, debido a la persistencia de una inflamación moderada en las paredes musculares del útero o el retraso de la involución uterina $(3,9,10)$.

\section{Arcanobacterium pyogenes (Coryne- bacterium-Actinomyces pyogenes).} Aunque es reconocido como ácido-alcohol resistente, de acuerdo con la tinción de Gram, se clasifica como Gram positivo. Suele considerarse un habitante normal de mucosa nasal, conjuntival, vaginal y prepucial en los rumiantes, aunque se ha encontrado relacionado con problemas reproductivos como aborto (11). Investigaciones realizadas en Iraq, reportaron que esta bacteria puede alojarse hasta 21 días post parto, generando una severa endometritis, lo que usualmente termina en infertilidad (12).

Se podría considerar que $A$. pyogenes es un organismo oportunista de las mucosas del bovino y que ante diferentes factores predisponentes puede originar infección (11). Generalmente se aísla en vacas cuyo intervalo parto/concepción se encuentra aumentado; coloniza el útero de la mayoría de las vacas postparto, ocasionando una metritis puerperal la cual se resuelve en pocos días si el animal no tiene problemas de fertilidad o no ha sufrido retención de membranas fetales (3).

Lactobacillus sp. Considerados como flora bacteriana normal en la cavidad oral, mucosa intestinal y vaginal; crecen generando un beneficio para su hospedero, debido a que la producción de ácido láctico reduce el $\mathrm{pH}$, contribuyendo a la disminución o al retraso del crecimiento de otro tipo de flora potencialmente patógena $(3,13)$. En la actualidad se está empleando esta bacteria como probiótico para la prevención de algunas infecciones reproductivas en diferentes animales incluidos los bovinos (14).

Klebsiella sp. Se ha clasificado como flora uterina normal en novillas (1). En una investigación realizada por Méndez (7) se determinó que el porcentaje de prevalencia para Klebsiella sp en el útero es bajo $(9.52 \%)$ y se concluyó que no es un patógeno asociado con problemas reproductivos, simplemente se considera como flora acompañante del útero de vacas donadoras de embriones (7).

Escherichia coli. Es un contaminante del tracto genital en vacas que se puede aislar unos días después del parto, con un porcentaje del $36 \%$ el cual se ha relacionado con contaminación de los machos (9). En Argentina, se reportó el aislamiento del microorganismo en un $29 \%$ de vacas que presentaron problemas del tracto reproductivo como metritis $y$ descargas uterinas con olor fétido (10).

Prevotella melaninogenica. En la actualidad esta bacteria ha cobrado gran importancia a nivel veterinario, debido a que se ha reconocido como un microorganismo patógeno, causante de problemas reproductivos e infecciones en el tracto urogenital de los bovinos, asociada principalmente con infecciones causadas por $E$. coli (15), adicionalmente se ha reportado asociación sinérgica con $A$. pyogenes en infecciones uterinas, incrementando el riesgo y la severidad de la endometritis en bovinos (15). $P$. melaninogenica produce leucotoxinas capaces de inhibir la fagocitosis alterando 
el mecanismo normal de defensa, lo que permite una mayor colonización del tejido (16); estudios realizados en Londres, han reportado que el crecimiento de esta bacteria se ve estimulado por la producción de estradiol hormona que se secreta en gran cantidad antes de la ovulación, por lo que se puede facilitar la presentación de problemas reproductivos como reabsorción embrionaria, metritis, endometritis y abortos, entre otras (17).

Clostridium sp. Las esporas liberadas por este microorganismo poseen elevada resistencia a los cambios ambientales, lo que les permite mantener su potencial infeccioso $(8,18)$. Los problemas reproductivos que se asocian con esta bacteria son la metritis tóxica, gangrenosa e incluso puede llegar a generar la muerte del animal (10). En Argentina se ha aislado Clostridium sp, a partir de lavados uterinos en vacas con problemas reproductivos (8).

El objetivo de este estudio fue evaluar la asociación entre los hallazgos citológicos con la presencia de flora bacteriana en lavados uterinos de bovinos con historia de problemas reproductivos en dos hatos del Altiplano Cundiboyacense.

\section{MATERIALES Y MÉTODOS}

Población de estudio y muestra. El estudio se realizó en dos hatos lecheros del Altiplano Cundiboyacense; el primero ubicado en el municipio de Sibaté (Cundinamarca), con una población de 322 vacas y el segundo ubicado en Ventaquemada (Boyacá), con una población de 71 hembras. Los criterios de inclusión fueron: 1) vacas vacías; 2) sin tratamiento antimicrobiano 15 días antes del muestreo y 3) con historia de problemas reproductivos como metritis, repetición de celo y abortos. Con base en los criterios de inclusión, fue posible muestrear el 3\% $(n=10)$ de los animales en el primer hato y $15.4 \% \quad(n=11)$ de los animales en el segundo hato.

\section{Obtención y transporte de las} muestras. Los lavados uterinos fueron obtenidos mediante la infusión de 40 a $50 \mathrm{ml}$ de solución salina fisiológica estéril dentro del cuerpo del útero con ayuda de una jeringa unida a una sonda o catéter tipo Folley 18 (3); el útero fue masajeado y retraído para recoger el líquido mediante aspiración con la jeringa, el cual se transfirió a un tubo cónico de $50 \mathrm{~mL}$, rotulado con el número del animal y el nombre de la finca. Las muestras fueron transportadas al laboratorio para su procesamiento en un periodo no superior a 6 horas a temperatura ambiente.

Evaluación macroscópica. La caracterización macroscópica de los lavados uterinos fue realizada determinando apariencia, color y presencia de sedimento.

Evaluación citológica. Los tubos cónicos de $50 \mathrm{ml}$ que contenían las muestras de los lavados, se llevaron a centrifugar por $10 \mathrm{~min}$ a $1000 \mathrm{rpm}$ para concentrar la flora bacteriana; luego de centrifugar se tomaron $100 \mu \mathrm{l}$ del sedimento para la realización de extendidos que fueron teñidos con Wright y Gram, con el fin de determinar la respuesta inflamatoria (mediante la presencia de células polimorfonucleares (PMN) y/o mononucleares (MN)) y presencia de células de descamación epitelial (CEDU), además de observar la morfología bacteriana.

Para la interpretación de las citologías analizadas se tuvo en cuenta una escala semicuantitativa considerando como respuesta inflamatoria leve la presencia de 1-5 PMN/campo, moderada de 6-10 PMN/ campo y severa >10PMN/campo.

Cultivo. Se determinó la presencia de microorganismos aerobios no exigentes, para lo cual se sembraron $100 \mu \mathrm{l}$ del sedimento de cada lavado uterino por agotamiento en agar sangre y en agar MacConkey, se incubaron por $24 \mathrm{~h}$ a $37^{\circ} \mathrm{C}$. Posteriormente se determinó el tipo de crecimiento bacteriano evaluando sus características macroscópicas y microscópicas por coloración de Gram y Ziehl-neelsen; además se realizó la identificación de género por medio de algunas pruebas bioquímicas como oxidasa, catalasa, hidrólisis de esculina, tolerancia 
al $\mathrm{NaCl}$ al $6.5 \%$, TSI, SIM, citrato, $\mathrm{H}_{2} \mathrm{~S}$, gelatina, urea, fermentación de azucares (glucosa, trehalosa, sucrosa, manitol, sorbitol, lactosa, xilosa).

Prueba de sensibilidad antimicrobiana. Se realizó la técnica de Kirby Bauer en Müeller Hinton adicionado con sangre al $5 \%$, para establecer patrones de sensibilidad y resistencia a estreptomicina $(10 \mu \mathrm{g})$, eritromicina $(30 \mu \mathrm{g})$, tetraciclina $(30 \mu \mathrm{g})$, gentamicina $(10 \mu \mathrm{g})$, amoxacilina con ácido clavulánico $(10 \mu \mathrm{g})$, ampicilina $(10 \mu \mathrm{g})$, norfloxacina $(10 \mu \mathrm{g})$, cefotaxime $(30 \mu \mathrm{g})$ y trimetoprimsulfa $(10 \mu \mathrm{g})(19)$.

Análisis estadístico. Se realizó un análisis de asociación mediante la prueba de $\chi^{2}$ con un nivel de significancia de 0,05 para determinar la posible asociación entre las variables Características macroscópicas Vs. presencia de flora bacteriana, hallazgos citológicos Vs. presencia de flora bacteriana, haciendo uso del software estadístico $\mathrm{R}$, bajo licencia freeware.

\section{RESULTADOS}

Evaluación macroscópica. De los 21 lavados uterinos obtenidos se observaron diferentes apariencias macroscópicas, entre las cuales había 5 muestras (23.8\%) totalmente translúcidas y sin sedimento, ocho turbias $(38.1 \%)$, dos sanguinolentas $(9.52 \%)$, dos mucopurulentas $(9.52 \%)$ y cuatro sanguino/ mucopurulentas (19\%) (Figura 1).

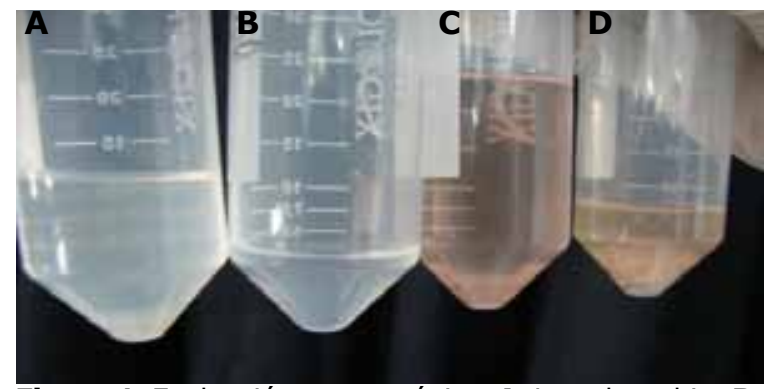

Figura 1. Evaluación macroscópica. A. Lavado turbio; B. Lavado translucido sin sedimento; C. Lavado con secreción sanguinolenta y $\mathbf{D}$. Lavado con secreción mucopurulenta.

Evaluación citológica. A partir de los 5 lavados translúcidos sin sedimento $(23.8 \%)$, no se encontró evidencia de CEDU ni respuesta inflamatoria mediada por PMN y/o MN, excepto en una muestra donde solamente se observaron ocasionales CEDUs; de los 16 lavados con apariencia anormal en 4 (25\%) se observaron CEDUs, en $3(18.75 \%)$ PMN, en $4(25 \%)$ CEDUs y PMN y en las 5 restantes (31.25\%) no se observó celularidad (Figura 2), en ninguna de las muestras evaluadas se evidenció respuesta de tipo mononuclear. La identificación microscópica de la flora bacteriana se realizó mediante tinción de Gram, la cual mostró un $28.57 \%$ de positividad, observándose bacilos y cocos gram positivos, además se obtuvieron 15 muestras $(71.43 \%)$ negativas para bacterias.

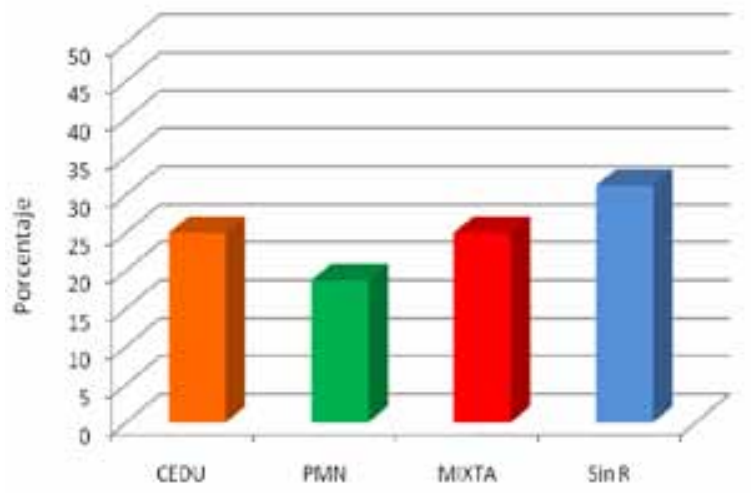

Figura 2. Evaluación citológica. CEDU (células de descamación uterina), PMN (Polimorfonucleares), Mixta (Respuesta mediada por PMN y CEDUs), sin R ( $\sin$ respuesta).

De acuerdo con la prueba $\chi^{2}$ para asociación, se observó una correlación directa entre las características macroscópicas y la citología de los lavados uterinos ( $p$-value $=0.004$ ).

Cultivo. Del total de las muestras, el $28.57 \%$ $(n=6)$ fue positivo para el aislamiento bacteriano, los géneros que predominaron fueron: Streptococcus sp. $\beta$ hemolítico con $33.33 \%(n=2)$, Streptococcus sp. Y hemolíticos $50 \%(n=3)$ y Streptococcus sp. a hemolíticos en $50 \% \quad(n=3)$, de acuerdo con las pruebas bioquímicas ninguno de los anteriores correspondió al género Enterococcus; Arcanobacterium pyogenes en $16.66 \%(n=1)$, Klebsiella $\mathrm{sp}$ con un $16.66 \%(n=1)$, y Lactobacillus $\mathrm{sp}$ con $16.66 \%(n=1)$. Por microscopía de campo oscuro directamente del sedimento de los lavados en dos (9.52\%) de las 21 muestras se observaron espiroquetas 
que de acuerdo con su morfología y motilidad pueden ser compatibles con Leptospira sp, en las que no se aisló ningún microorganismo. De acuerdo con el análisis estadístico se observó una asociación entre las características macroscópicas y la positividad en el cultivo ( $p$-value=0.027), así como entre este último y los hallazgos citológicos $(p-$ value $=0.009)($ Tabla 1$)$.

Tabla1. Hallazgos macroscópicos, citológicos y bacteriológicos en los lavados uterinos evaluados.

\begin{tabular}{|c|c|c|}
\hline $\begin{array}{l}\text { ASPECTO } \\
\text { DEL LAVADO } \\
\text { UTERINO }\end{array}$ & CITOLOGÍA & $\begin{array}{l}\text { BACTERIAS } \\
\text { AISLADAS }\end{array}$ \\
\hline $\begin{array}{l}\text { Translucidos } \\
(n: 5)\end{array}$ & Presencia de CEDU & $\begin{array}{l}\text { No se encontró flora } \\
\text { bacteriana }\end{array}$ \\
\hline Turbio (n:8) & $\begin{array}{l}\text { Moderada rta mediada } \\
\text { por PMN, con } \\
\text { presencia de cocos } \\
\text { Gram positivos (+++) } \\
\text { y presencia de CEDU }\end{array}$ & $\begin{array}{l}\text { Streptococcus sp a y } \\
\text { y hemolítico }(n: 3) \text { y } \\
\text { espiroqueta }(n: 1)\end{array}$ \\
\hline $\begin{array}{l}\text { Secreción } \\
\text { sanguinolenta, } \\
\text { mucopurulenta, } \\
\text { sanguino/ } \\
\text { mucoporulenta } \\
(n: 8)\end{array}$ & $\begin{array}{l}\text { Moderada rta mediada } \\
\text { por PMN, presencia de } \\
\text { cocos Gram positivos } \\
(+) \text {, Gram negativos } \\
\text { y presencia de CEDU }\end{array}$ & $\begin{array}{l}\text { Actinomyces pyogenes } \\
(\mathrm{n}: 1), \text { Streptococcus } \\
\mathrm{sp}(\mathrm{n}: 4)(\beta, \mathrm{\gamma}, \mathrm{a} \\
\text { hemolíticos), } \\
\text { Lactobacillus sp }(\mathrm{n}: 1), \\
\text { Klebsiella sp }(\mathrm{n} ; 1), \\
\text { espiroqueta }(\mathrm{n}: 1)\end{array}$ \\
\hline
\end{tabular}

Prueba de sensibilidad antimicrobiana.

El antibiograma fue realizado para los aislamientos de $A$. pyogenes y Streptococcus $\beta$, a y $\mathrm{Y}$ hemolíticos. El asilamiento de $A$. pyogenes mostró resistencia a estreptomicina y sensibilidad a gentamicina, amoxacilina con ácido clavulánico, ampicilina, norfloxacina y cefotaxime como se evidencia en la figura 3A. En el caso de Streptococcus Y y a hemolíticos, los dos presentaron los mismos patrones de sensibilidad y resistencia siendo sensibles para eritromicina, tetraciclina y amoxacilina con ácido clavulánico y resistentes a trimetoprimsulfa, gentamicina $y$ estreptomicina (Figura 3B). El antibiograma para Streptococcus $\beta$ hemolítico demostró resistencia a la eritromicina, amoxacilina con ácido clavulánico y trimetoprimsulfa y sensibilidad a gentamicina, tetraciclina y estreptomicina.

\section{DISCUSIÓN}

En condiciones normales, los lavados uterinos realizados con solución salina deben tener una apariencia translucida y sin olor, no deben mostrar secreciones ni conglomerados; cuando se presentan infecciones $o$ problemas en el tracto urogenital se evidencian secreciones mucopurulentas o sanguinolentas, además de olor fétido en algunos casos por presencia de bacterias (3). En este trabajo se observaron diferentes apariencias, desde lavados translucidos hasta lavados sanguino-mucopurulentos.

La evaluación microscópica mediante las tinciones de Wright y Gram es de gran utilidad para la identificación de una respuesta inflamatoria mediada por PMN - MN, la presencia de CEDUs y de flora bacteriana acompañante $(2,8)$, como se pudo corroborar en este estudio.

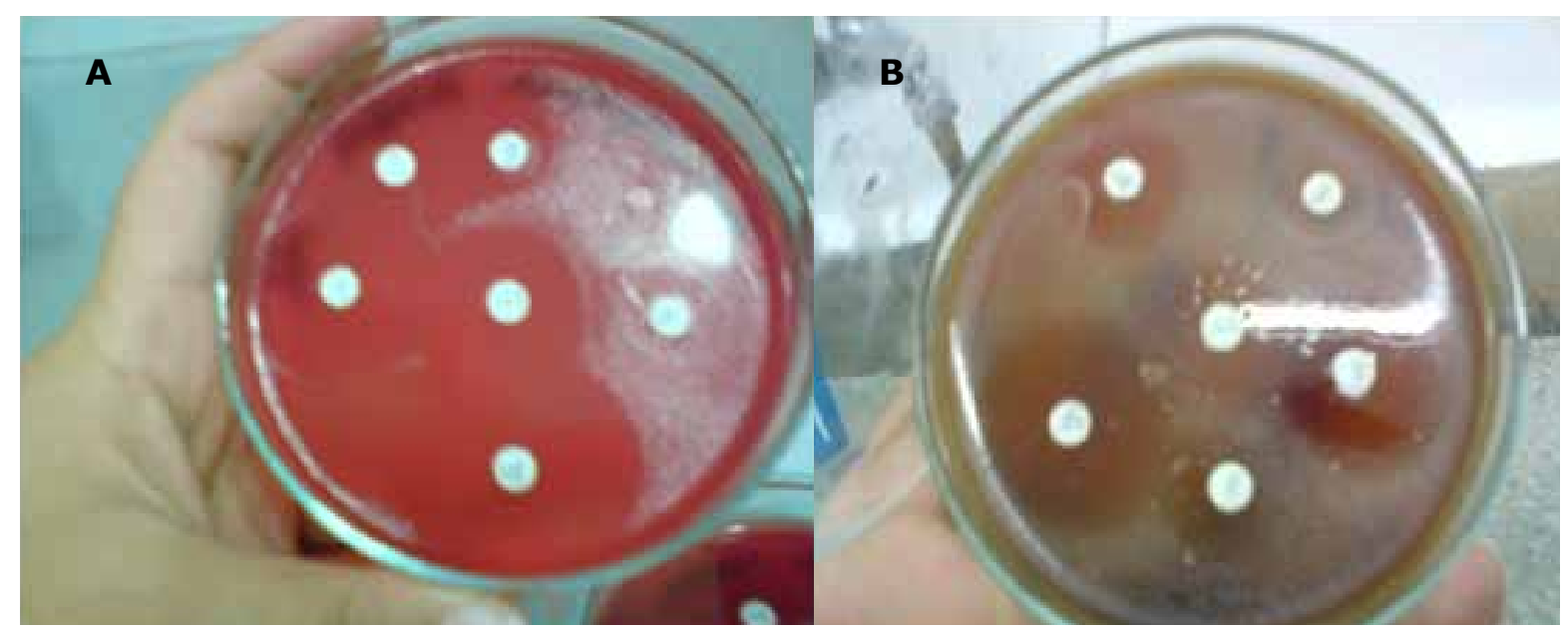

Figura 3. Antibiogramas. A. Prueba de sensibilidad para A. pyogenes y B. para Streptococcus $y$ hemolítico. 
La respuesta inflamatoria mediada por PMN y/o MN, es uno de los parámetros de mayor importancia al evaluar el estado inmunológico del animal frente a una patología uterina (3), sin embargo, fisiológicamente también se pueden observar PMN en una proporción leve durante la fase del estro sin que esto implique un proceso infeccioso, como se indicó en un estudio realizado en Canadá en el que se demostró que obtener más del $5 \%$ de PMN es indicativo de una inflamación endometrial y $>10 \%$ de endometritis (20).

Las CEDUs, en general se hallaron en poca proporción, lo que puede ser considerado como normal en algunas fases del ciclo reproductivo como lo es el metaestro, donde el animal ovula normalmente presentando un bajo efecto de estrógenos y altos niveles de progesterona producida en el cuerpo lúteo, lo que lleva a un aumento en la descamación celular; pero si se observan en gran proporción, se deben considerar otras patologías como una posible vulvitis, metritis, retención de placenta e incluso abortos, los cuales se pueden relacionar con infecciones venéreas (21).

La prueba de $\chi^{2}$ evidenció una asociación entre los hallazgos macroscópicos y citológicos $(p$-value $=0.004)$ de los lavados uterinos, lo que puede sugerir por ejemplo, que el aspecto macroscópico de una muestra puede indicar el grado de inflamación que se esperaría encontrar en el análisis citológico así: una apariencia turbia sugeriría una ligera respuesta celular, ya sea por descamación o por inflamación.

El $28.57 \%$ de los lavados fueron positivos para el cultivo microbiológico, correspondientes a las muestras que tenían apariencia turbia, sanguinolenta y/o mucopurulenta, esta asociación directa se comprobó estadísticamente mediante la prueba de $\chi^{2}(p$-value $=0.027)$

Klebsiella sp y Lactobacillus sp son bacterias que se encuentran como flora habitual en tracto reproductivo y por su naturaleza no causan alteraciones o problemas reproductivos $(3,13,22)$. En un estudio realizado en Montería, Colombia se identificó a Klebsiella sp en un $32.4 \%$ de los casos como una bacteria que hace parte de la flora acompañante en vacas, ya que no se encontró relacionada a patologías del tracto genital en bovinos ni a la monta natural o a la inseminación artificial (1), lo que difiere de lo observado en este estudio, ya que aunque el porcentaje de aislamiento fue bajo (16.66\%) se debe tener en cuenta que el microorganismo se aisló a partir de un lavado uterino de aspecto sanguinolento con respuesta inflamatoria mediada por PMN. En Cuba y Estados Unidos, se confirmó la presencia del Lactobacillus sp como flora normal cervical y uterina en vacas, generando beneficios a su hospedero, gracias a la producción del acido láctico que inhibe flora patógena $(3,5)$. Sin embargo, de acuerdo con los resultados obtenidos para este caso aparentemente no desempeñó el papel inhibidor ya que se encontró en una muestra con apariencia sanguinolenta y mucopurulenta, con respuesta inflamatoria y en asociación con Streptococcus sp. $\beta$ y y hemolíticos.

Por otra parte, Arcanobacterium pyogenes (Corynebacterium-Actinomyces pyogenes) ha sido estudiado por sus implicaciones en abortos en ganado lechero; esta bacteria es comúnmente encontrada en mucosa prepucial, vaginal y en útero (8); en investigaciones realizadas en Colombia se encontró a este agente patógeno como el principal causante de problemas reproductivos asociados a metritis (23), endometritis (7), placentitis supurativa y bajos porcentajes de fertilidad (23), encontrándose en un $10 \%$ de la población en estudio, siendo este resultado cercano al obtenido en este trabajo (16.66\%).

Azawi (12) y Roppel y Campero (24) reportan la asociación de $A$. pyogenes con $E$. coli como causantes de infecciones uterinas postparto en bovinos en un $69 \%$ de los animales evaluados; en estudios realizados en Cuba, se determinó que $A$. pyogenes es un agente altamente patógeno que causa severas inflamaciones del útero y que también se encuentra en el semen de los toros, siendo este el medio de transmisión a las hembras 
independientemente de que sea por monta directa o inseminación artificial (25). En el caso especifico de este estudio y con base en el análisis de las historias clínicas, la hembra con aislamiento positivo para esta bacteria mostró baja tasa de fertilidad, manifestada en sucesivas repeticiones de celo, lo que concuerda con los reportes descritos anteriormente, por tanto se debe tener precaución con la manipulación de elementos como las mangas de palpación y demás implementos que entren en contacto directo con el conducto vaginal, para evitar que este patógeno se propague en el hato y cause serios problemas reproductivos (3).

Microorganismos como los Streptococcus sp. $Y, \beta$ y a hemolíticos son agentes infecciosos que se pueden transmitir fácilmente por el líquido seminal (25), causando infecciones uterinas y problemas inflamatorios como endometritis y metritis, llegando a ser en ocasiones purulentas por la asociación con otras bacterias o simplemente por la alta colonización de éstas (3). Estos microorganismos fueron aislados de animales que presentaban metritis y secreción mucopurulenta posiblemente asociada a estas bacterias, hallazgos que concuerdan con investigaciones hechas en Argentina donde se encontró Streptococcus sp en vacas lecheras con problemas de metritis, siendo este el agente causal de dicha patología en animales post parto (10). En Colombia, se aisló Streptococcus a-hemolítico en cuadros de endometritis bovina, asociado a $E$. coli y $A$. pyogenes (7); sin embargo, en estudios hechos en Cuba, se determinó que esta bacteria puede llegar a ser microbiota normal de secreciones cérvico-uterinas de vacas clínicamente sanas, además de estar presente en infecciones puerperales luego de los primeros 15 días post-parto (3). Los animales muestreados a los cuales se les asiló Streptococcus $\gamma$, a y $\beta$ hemolíticos, evidenciaron secreciones mucopurulentas en gran proporción y metritis, además de ser vacas recién paridas de acuerdo con lo reportado en la historia clínica, lo que se puede asociar con la presencia de esta bacteria, debido a que son microorganismos habitualmente patógenos piógenos (7).
Las pruebas de sensibilidad antimicrobiana se realizaron para sugerir el posible tratamiento farmacéutico de elección; sin embargo, se evidenciaron diferentes patrones de comportamiento frente a los antibióticos evaluados, estos resultados deben ser tenidos en cuenta para la implementación de la terapia más adecuada, además de considerar que la eficacia de ésta puede estar influenciada por múltiples factores con posibles variaciones o efectos en el animal (19).

En este estudio se evidenció que los antibióticos que se podrían utilizar para el tratamiento de los problemas reproductivos de origen bacteriano son la gentamicina y la tetraciclina; aunque en el caso de la gentamicina esta se utiliza principalmente para Gram negativos se ha observado que también puede tener efecto sobre algunos Streptococcus sp y Staphylococcus $\mathrm{sp}$, mientras que la tetraciclina es un bacteriostático de amplio espectro que en altas concentraciones puede ser bactericida, como se evidenció en un estudio realizado en Slovakia (26) donde se demostró que la tetraciclina es una alternativa en el manejo de estas enfermedades, debido a su rápida acción en el útero.

Los resultados observados para $A$. pyogenes y Streptococcus sp indicaron un patrón de resistencia frente a estreptomicina, lo que concuerda con lo reportado por Solórzano et al (27) quienes asocian este comportamiento al uso indiscriminado del antibiótico para el tratamiento de los problemas reproductivos en vacas.

La presencia de bacterias patógenas en el tracto reproductivo de los bovinos, sugiere la implementación de medidas de bioseguridad estrictas, para evitar su transmisión a la población expuesta y vulnerable lo que puede llegar a ser de gran relevancia, dado los problemas reproductivos y las pérdidas económicas considerables que esto implicaría.

Al analizar la información, se puede concluir que las características macroscópicas, la citología y el cultivo microbiológico se encuentran relacionados directamente, lo 
cual podría asociarse con la historia clínica de problemas reproductivos en los hatos.

Como recomendación es necesario tener en cuenta que la bioseguridad en las ganaderías debe implementarse a todos los niveles (ordeño, inseminación, alimentación, entre otros), para evitar un aumento progresivo de bacterias patógenas, que puedan causar problemas reproductivos y puedan afectar la economía del hato.

\section{Agradecimientos}

A los propietarios y trabajadores de las fincas por facilitarnos la realización del estudio. Al Dr. Olimpo Oliver E. de la Clínica para Grandes Animales de la Facultad de Medicina Veterinaria y de Zootecnia de la Universidad Nacional de Colombia por su colaboración.

\section{REFERENCIAS}

1. González M, Ríos M, Mattar S. Prevalencia de bacterias asociadas a la infertilidad infecciosa en bovinos de Montería. Rev MVZ Córdoba 2007; 12(2): 1028-1035.

2. Biberstein E, Chung Y. Bacterias. En: Tratado de microbiología veterinaria. España: Acribia, 1990; 15: 6-10.

3. Fernández A, Silveira E, López O. Las infecciones uterinas en las hembras bovinas. REDVET 2006; 7(10):1-39.

4. Gilbert R, Shin S, Guard C, Erb H. Prevalence of endometritis and its effects on reproductive performance of dairy cows. Theriogenology 2005; 9:1879-1888.

5. Santos N, Lamd G, Brown D, Gilbert R. Postpartum endometrial cytology in beef cows. Theriogenology 2009; 71:739-745

6. Arambula A. Coloración de gram en el diagnóstico de las infecciones uterinas. Revista Salud UIS 2004; 36: 132-137.

7. Méndez D. Determinación de la microflora bacteriana uterina en vacas donantes de embriones. [Trabajo de grado]. Bogotá, Colombia: Pontificia Universidad Javeriana; 2008.
8. Palmer C. Endometritis en vacas lecheras. En: Jornadas de actualización en biotecnologías de la reproducción bovina del IRAC. Argentina: Universidad de Saskatchewan; 2008.

9. Rodríguez G. Principales características y diagnóstico de los grupos patógenos de Escherichia coli. Salud pública Méx 2002; 44: 464-475

10. Palmer C. Metritis postparto en vacas lecheras. En: Jornadas de actualización en biotecnologías de la reproducción bovina del IRAC. Argentina: Universidad de Saskatchewan, 2008.

11. Araínga $M$, Sandoval $N$, Zacarías $E$, Rivera $\mathrm{H}$. Actinomyces pyogenes causante de abortos en bovinos. Rev Investig Vet Perú 2003; 14(1): 86-88

12. Azawi O. Review: Postpartum uterine infection in cattle. Rev Anim Reprod Sci 2008; 105(3-4): 187-208.

13. Vadillo S, Píris S, Mateos E. Manual de microbiología veterinaria. Madrid, España: Editorial McGraw Hill interamericana; 2002.

14. Otero C, Silva C, Wilde O, Ruiz A, Nader-Macias M. Variaciones de Lactobacillus y Enterococcus aislados de vagina de vacas durante ciclo estral. En: 22 congreso argentino de producción animal. Argentina: Universidad de Tucamán; 1998. 
15. Sheldon M, Williams E, Miller A, Nash $D$, Herath S. Uterine diseases in cattle after parturition. Rev Vet J 2008; 176(1):115-121.

16. Sheldon $M$, Dobson $H$. Postpartum uterine health in cattle. Rev Anim Reprod Sci 2004; 82:295-306.

17. Sheldon M, Noakes D, Rycroft A, Dobson $\mathrm{H}$. Effect of intrauterine administration of oestradiol on postpartum uterine bacterial infection in cattle. Rev Anim Reprod Sci 2004; 81(1-2): 13-23.

18. Moat A, Foster J. Microbial Physiology 2da edition. United State of America: Editorial Jhon Wiley and Sons; 1988; $1: 1-50$.

19. Arias M, Monge R, Artavia J, González P. Antimicrobial susceptibility pattern of Gram negative bacterias isolated from enteral feeding. Rev Biomed $2000 ; 11: 169-174$.

20. Barlund C, Carruthers T, Waldner C, Palmer C. A comparison of diagnostic techniques for postpartum endometritis in dairy cattle. Theriogenology 2008; 69:714-724.

21. Rimbaud E. Infertilidad y esterilidad en la hembra. En: Fisiopatología de la reproducción. España: Universidad de Ciencias Comerciales. 2005.
22. Farinati A, Mormandi J, Tilli M. Flora habitual cérvicovaginal. En: Infecciones en ginecología y obstetricia del diagnostico al tratamiento. Argentina: Color Press S.R.L; 2005.

23. Gutiérrez D, Fonseca C. Efectividad del producto homeopático metrix-H en el tratamiento de la endometritis bovina. [Trabajo de grado]. Bogotá, Colombia: Universidad de la Salle; 2000.

24. Roppel M, Campero C. Acción de Actinomyces pyogenes en el tracto reproductivo bovino. Revista Therios $1998 ; 27: 14-20$.

25. Silveira E, Machado R. Flora bacteriana del semen de toros antes y después de la congelación. REDVET 2005; 6(10):1695-7504.

26. Hajurka J, Nagy J, Popelka P, Róźańska $\mathrm{H}$, Sokol J, Cabadaj R y Hura V. Tetracycline concentrations in blood and milk of cow following intrauterine treatment of acute or subacute/ chronic endometritis. Bull Vet Inst Pulawy 2003; 47: 435- 447.

27. Solórzano Z, Lozano R, y Gonzalez E. Evaluación de diferentes tratamientos en el posparto temprano vacas lecheras con infecciones uterinas. Rev Téc Pecu Méx 2002; 40(1):105-117. 